\title{
Rapid referral for headache management from emergency department to headache centre: four years data
}

\author{
Andrea Negro ${ }^{1,2^{*}}$ (D), Valerio Spuntarelli ${ }^{1}$ (D, Paolo Sciattella ${ }^{3}$ (D) and Paolo Martelletti ${ }^{1,2}$ (I)
}

\begin{abstract}
Background: Headache is one of the most common reason for medical consultation to emergency department (ED). The inappropriate use of ED for non-emergency conditions is a problem in terms of overcrowding of emergency facilities, unnecessary testing and treatment, increased medical costs, burden on medical service providers and weaker relationships between patient and primary care provider. The aim of this study was to analyze the different stages of ED management of headache to identify those deficiencies that can be overcome by a fast referral to a headache clinic.

Methods: The study is a retrospective analysis of the electronic medical records of patients discharged from an academic ED between January 1, 2015 and December 31, 2018 and referred to the tertiary level headache centre of the same hospital. We analyzed all aspects related to the permanence in ED and also assessed whether there was a match between the diagnosis made in ED and ours.

Results: Among our sample of 244 patients, 76.2\% were admitted as "green tag", 75\% underwent a head computed tomography, 19.3\% received a neurological consultation, 43\% did not receive any pharmacological treatment and $62.7 \%$ still had headache at discharge. The length of stay in ED was associated with reporting the first aura ever $(p=0.014)$ and whether patients received consultations $(p<0.001)$. The concordance analysis shown a significant moderate agreement only for the diagnosis of migraine and only between triage and headache centre.

Conclusions: Most patients who went to ED complaining of headache received the same treatment regardless of their diagnosis and in many cases the headache had not yet resolved at the time of discharge. Given the many shortcomings in headache management in ED, rapid referral to the headache centre is of paramount importance to help the patient achieve a definiteve diagnosis and appropriate treatment.
\end{abstract}

Keywords: Headache, Migraine, Non-traumatic headache, Emergency department

\section{Introduction}

Headache is one of the most common symptoms and an important reason for medical consultation and presentation to emergency departments (EDs). In fact, of all patients visiting EDs, up to $4.5 \%$ report that non-traumatic

\footnotetext{
* Correspondence: andrea.negro@uniroma1.it

${ }^{1}$ Department of Clinical and Molecular Medicine, Sapienza University, Rome, Italy

${ }^{2}$ Regional Referral Headache Centre, Sant'Andrea Hospital, Rome, Italy

Full list of author information is available at the end of the article
}

headache is their main complaint [1]. The third edition of the International Classification of Headache Disorders (ICHD-III) distinguishes between secondary headaches, where headache is a symptom, and primary headaches, which include migraine (with or without aura), tensiontype headache and the group of trigeminal autonomic cephalalgias (TACs) for which cluster headache counts for the majority [2]. Migraine alone is the world's second leading cause of years of life lived with disability [3] and 
chronic migraine $(\mathrm{CM})$ patients, who have $\geq 15$ headache days per month, are more likely to have a higher disability, lower quality of life and greater use of healthcare resources than patients with episodic migraine (EM) $[4,5]$.

In the ED, as in the general population, primary headache disorders are much more common than secondary disorders and it can be challenging for ED doctors to distinguish the few patients with potentially life-threatening headaches from the vast majority with benign headaches [6]. Primary headache is diagnosed in $58-81.2 \%$ of ED patients with headache and, for the specific diagnosis of primary headache, migraine is the main condition, representing $17-64 \%$ of cases [7-11]. While most headaches have a benign etiology and are selflimiting, up to $5 \%$ have a serious and life-threatening cause (e.g., subarachnoid hemorrhage) that requires immediate medical attention $[12,13]$.

Inappropriate use of ED for non-emergency conditions is a problem in terms of overcrowding of emergency facilities, unnecessary testing and treatment, increased medical costs, burden on medical service providers and weaker relationships between patient and primary care provider. Studies evaluating this phenomenon have found that the inability to take time off from school or work during the day and the ease of use of emergency care without the need for an appointment are cited as a reason for their consultation by a significant percentage of patients, suggesting that inappropriate use of ED could be a matter of personal convenience [14, 15]. An observational study investigated the factors associated with ED visits for headache and found that the most common reason for visiting ED was a perceived emergency condition or referral by a physician (33.3\%) [16]. The other most commonly cited reasons were the timeliness of the treatment, either because the doctor's office was closed (20\%) or because patients could not get an appointment early enough (11\%), or because they did not have a doctor or no other place to go (9\%) [17]. Studies conducted in other countries suggest that primary headaches are under- or misdiagnosed and, as a result, patients are often undertreated or receiving inadequate care when consulting an $\mathrm{ED}[8,17,18]$.

In our hospital there is close collaboration with ED and all patients suffering from headache after discharge can be referred to our clinic and visited within $36 \mathrm{~h}$.

Given the lack of Italian studies on patients presenting with headache to ED, we analyzed the different stages of headache management to identify the deficiencies that can be overcome with a quick referral to a headache clinic. In particular, we evaluated the demographic and clinical features of these patients, the frequency and accuracy of headache diagnosis, the treatment they received and their followup in our headache center.

\section{Methods}

The study is a retrospective analysis of the electronic medical records (EMRs) of patients who presented to the academic ED of Azienda Ospedaliera Sant'Andrea, between January 1, 2015 and December 31, 2018, with a chief compliant of headache and who, after discharge, were referred to the Regional Referral Headache Centre, Department of Clinical and Molecular Medicine, Faculty of Medicine and Psychology, Sapienza University of Rome.

\section{Data collection}

The data analyzed included basic demographic information, presentation time, priority assessment and diagnosis of admission by the hospital triage nurse, door-todoctor time and the length of stay in ED, life parameters, diagnostic investigations, specialist consultations, treatment administration and discharge diagnosis. We also assessed the time elapsed between discharge from the ED and the first visit to our headache center and whether there was a match between the diagnosis of discharge from the ED and ours.

For priority admission, our ED uses an advanced triage system that provides a color-coding scheme that uses white, green, yellow and red tags to define conditions at an increasing level of severity:

- white tags - (dismiss) are given to those with minor injuries for whom a doctor's care is not required;

- green tags - (wait) are reserved for the "walking wounded" who will need medical care at some point, after more critical injuries have been treated;

- yellow tags - (observation) for those who require observation (and possible later re-triage). Their condition is stable for the moment and, they are not in immediate danger of death. These victims will still need hospital care and would be treated immediately under normal circumstances;

- red tags - (immediate) are used to label those who cannot survive without immediate treatment but who have a chance of survival.

For vital signs analysis, elevated blood pressure (BP) was defined as follows: systolic BP (SBP) $\geq 140 \mathrm{mmHg}$ or diastolic BP (DBP) $\geq 90 \mathrm{mmHg}$ [19].

The diagnosis in our headache centre was made on the basis of the beta version or the final version of the ICHD-III depending on the year in which the visit was carried out $[2,20]$.

\section{Statistical analyses}

A descriptive analysis of the sample characteristics was carried out. The categorical data were summarized by numbers and percentages, the continuous data by mean and standard deviation. The association between total time in ED and follow-up at the headache centre was evaluated by Mann-Whitney tests. The concordance 
between primary headaches diagnosis was assessed using the Cohen Kappa coefficient ( $\mathrm{k}$ ). The significance level was set at 0.05 (always corrected if necessary). All analyses were performed using SAS 9.4 (SAS Institute Inc., Cary, NC, USA).

\section{Results}

Demographics and clinical characteristics of the study population

Demographic and clinical characteristics of patients treated in ED are summarized in Table 1. The sample analyzed consisted of 244 patients, 192 (78.7\%) women and $52(21.3 \%)$ men, aged between 14 and 89 years and an average of 40.7 years. After evaluating the general conditions, the triage nurses coded one patient $(0.4 \%)$ as a white tag, $186(76.2 \%)$ as a green tag, $56(23.0 \%)$ as a yellow tag and one patient $(0.4 \%)$ as a red tag. Medical history was negative for any conditions in 157 (64.3\%) patients. Among the various pathologies, the most frequent were hypertension (in $11.1 \%$ of patients), psychiatric disorders (in $8.6 \%$ of patients) and thyroid diseases (in $7.0 \%$ of patients). Patients presented to ED after an average of 1.9 days after the onset of the headache for which they needed assistance. The appearance of a migraine aura was the main reason for consulting for ED for 40 (16.4) patients and for $16(40 \%)$ of them it was the first aura of their lives. Mean values of vital signs for the whole sample of patients were in the normal range: systolic pressure was $130 \mathrm{mmHg}$ (range: 100-190), diastolic pressure was $77 \mathrm{mmHg}$ (range: 50-111), heart rate was $78 \mathrm{bpm}$ (range: $39-116$ ), temperature was $36.6{ }^{\circ} \mathrm{C}$ (range: 35.9-38) and oxygen saturation was 98\% (range: 94-100).

\section{Diagnosis of headache in the emergency department}

Table 2 summarized the changes in diagnoses in relation to the setting of the clinical evaluation. We found eleven different admission diagnoses assessed by the triage nurse. The three most common diagnoses were headache (63.6\%), migraine without aura (9.0\%) and ophthalmic headache (6.6\%). ED physicians used fewer diagnoses (four) and the most frequent was headache (52.5\%).

\section{Headache investigations received in the emergency department}

Most patients performed complementary examinations for diagnosis (Table 3). The most common investigation was head computed tomography (CT) required for 183 (75\%) patients. One patient with a known diagnosis of migraine refused to have a CT scan. Of the $182 \mathrm{CT}$ scans performed 171 (94\%) were negative and 11 (6\%) had findings that were all considered incidental: sphenoid and maxillary sinus mucosal thickening (3), mega cisterna magna (2), sinusitis (1), chronic ischemic
Table 1 Demographic and clinical characteristics of patients treated in the emergency department

\begin{tabular}{|c|c|}
\hline \multicolumn{2}{|l|}{ Demographics } \\
\hline age (years) (SD) & $40.7(16.3)$ \\
\hline sex (female) & $192(78.7)$ \\
\hline \multicolumn{2}{|l|}{ Medical history } \\
\hline negative & $157(64.3)$ \\
\hline hypertension & $27(11.1)$ \\
\hline psychiatric disorders & $21(8.6)$ \\
\hline thyroid disorders & $17(7.0)$ \\
\hline hematologic disorders & $10(4.1)$ \\
\hline dyslipidemia & $9(3.7)$ \\
\hline DM type 2 & $8(3.3)$ \\
\hline cerebrovascular diseases & $7(2.9)$ \\
\hline COPD/asthma & $4(1.6)$ \\
\hline ischemic heart disease & $3(1.2)$ \\
\hline solid tumor & $3(1.2)$ \\
\hline \multicolumn{2}{|l|}{ Time of ED presentation } \\
\hline 08:00-15:59 & $147(60.3)$ \\
\hline 16:00-23:59 & $79(32.4)$ \\
\hline 00:00-07:59 & $18(7.4)$ \\
\hline \multicolumn{2}{|l|}{ Headache onset } \\
\hline days bedore ED visit & $1.9(5.7)$ \\
\hline \multicolumn{2}{|l|}{ Triage codes } \\
\hline white & $1(0.4)$ \\
\hline green & $186(76.2)$ \\
\hline yellow & $56(23.0)$ \\
\hline red & $1(0.4)$ \\
\hline \multicolumn{2}{|l|}{ Vital signs } \\
\hline systolic BP (mmHg) & $130(16.9)$ \\
\hline diastolic BP (mmHg) & 77 (10.6) \\
\hline heart rate (bpm) & $78,910.60$ \\
\hline temperature $\left({ }^{\circ} \mathrm{C}\right)$ & 36.6 \\
\hline oxygen saturation (\%) & $98(1.4)$ \\
\hline \multicolumn{2}{|l|}{ Aura } \\
\hline reason to access ED & $40(16.4)$ \\
\hline first aura in their life & 16 of $40(40.0)$ \\
\hline \multicolumn{2}{|l|}{ ED times in min, mean (SD) } \\
\hline door-to-doctor time & 139 (118.4) \\
\hline time of care & $241(269.8)$ \\
\hline ED length of stay & $381(307.7)$ \\
\hline
\end{tabular}

$D M$ diabetes mellitus, $E D$ emergency department, $S D$ standard deviation

leukoencephalopathy (1), < $5 \mathrm{~mm}$ engagement of cerebellar tonsils into the foramen magnum (1), subcutaneous sebaceous cyst (1), aneurysm of basilar artery (1) and occipital bone exostoses (1). The second most common investigation was electrocardiogram (ECG) performed in 
Table 2 Changes in diagnoses in relation to the clinical evaluation setting

\begin{tabular}{|c|c|c|c|c|}
\hline DIAGNOSIS & $\begin{array}{l}\text { TRIAGE } \\
\text { nurse } \\
\text { (244 patients) }\end{array}$ & (244 patients) & $\begin{array}{l}\text { Headache } \\
\text { centre } \\
\text { (240 patients) }\end{array}$ & $\begin{array}{c}\text { Concordance TRIAGE - headache } \\
\text { centre } \\
(\kappa ; p \text {-value })\end{array}$ \\
\hline Headache & $155(63.6)$ & $128(52.5)$ & - & \\
\hline Migraine without aura & $22(9.0)$ & $82(33.6)$ & $140(57.4)$ & $0.581 ; p<0.001$ \\
\hline Migraine with aura (ophthalmic headache) & $16(6.6)$ & - & $34(13.9)$ & $0.032 ; p=0.586$ \\
\hline Tension-type headache & - & - & $32(13.1)$ & - \\
\hline Chronic migraine & - & - & $35(14.3)$ & - \\
\hline Medication overuse headache & - & - & $31(12.7)$ & - \\
\hline Cluster hedache & $2(0.8)$ & $2(0.8)$ & $7(2.9)$ & $-0.013 ; p=0.001$ \\
\hline Other TACs & - & - & $1(0.4)$ & - \\
\hline Trigeminal neuralgia & $8(3.3)$ & - & $3(1.2)$ & - \\
\hline Headache attributed to trauma & $5(2.1)$ & $32(13.1)$ & $8(3.3)$ & - \\
\hline Sinusitis & - & - & $2(0.8)$ & - \\
\hline $\begin{array}{l}\text { Headache attributed to cranial and/or cervical vascular } \\
\text { disorder }\end{array}$ & $16(6.6)$ & - & $6(2.5)$ & - \\
\hline Headache and arterial hypertension & $10(4.1)$ & - & $5(2.0)$ & - \\
\hline Headache and systemic infection & $6(2.5)$ & - & $1(0.4)$ & - \\
\hline Headache and anxiety disorder & $3(1.2)$ & - & - & - \\
\hline Cervicogenic headache & $1(0.4)$ & - & - & - \\
\hline
\end{tabular}

TACs trigeminal autonomic cephalalgias

Triage nurses used the definition "ophthalmic headache" to indicate the diagnosis of "migraine with aura"

The concordance between primary headaches diagnosis was assessed using the Cohen Kappa coefficient (K). The significance level was set at 0.05

There was not agreement between diagnoses made by ED physicians and headache centre

$31(12.7 \%)$ patients without any correlation with vital signs. All ECGs were reported as non-pathological. Finally, 16 (6.6\%) patients underwent other investigations besides head CT and ECG: supra-aortic trunk echodoppler (8), sinus CT scan (3), brain magnetic resonance imaging (MRI) (2), cervical X-rays (2) and electroencephalogram (1).

\section{Specialist consultations received in the emergency department}

Most patients were managed by ED physicians without the need for specialist consultation (Table 3). Of a total population of 244 patients, 47 (19.3\%) were examined by a neurologist, $7(2.9 \%)$ by an ophthalmologist, 5 (2.0\%) by an otolaryngologist, $5(2.0 \%)$ by a psychiatrist, 2 $(0.8 \%)$ by a cardiologist and $2(0.8 \%)$ by a neurosurgeon.

\section{Headache treatment received in the emergency department}

Pharmacological treatments administered in ED are summarized in Table 3. NSAIDs and weak opioids were the most commonly prescribed pharmacological agents, being administered in $44.3 \%$ and $17.6 \%$. of patients respectively. None of the 244 patients received a triptan. Treatment of associated symptoms included antiemetics and anxiolytics, administered to $12.7 \%$ and $4.9 \%$ of patients respectively. Proton pump inhibitors were administered to $10.2 \%$ of patients. Approximately $43 \%$ of patients received no pharmacological treatment, while among patients treated $25 \%$ received monotherapy, and $18.4 \%$ and $9.8 \%$ received a combination of two or three pharmacological agents, respectively.

\section{Triage and stay information in the emergency department}

Information on ED stay of the 244 patients is summarized in Table 4. The median door-to-doctor time was 139 (range: 3-881), the median time of care (from first contact with ED to discharge) was $241 \mathrm{~min}$ (range: 11404 ) and the mean time of stay (from arrival in ED to discharge) was $381 \mathrm{~min}$ (range: 20-2212). There was no significant correlation between the length of stay in ED and a number of factors (arrival time in ED, triage coding, blood pressure, head CT scan, ECG, other investigations and treatment administration). In contrast, the length of time spent in ED was significantly associated with some factors. In particular, having received neurological consultation $(p<0.001)$ or other specialist visits $(p=0.001)$ was associated with a longer stay in ED while the complaint of the first aura ever $(p=0.014)$ was associated with a shorter stay in ED. 
Table 3 Interventions in the emergency department

\begin{tabular}{lc}
\hline Investigations & \\
head CT & $183(75.0)$ \\
ECG & $31(12.7)$ \\
other & $16(6.6)$ \\
Specialist consultations & \\
neurologist & $47(19.3)$ \\
ophthalmologist & $7(2.9)$ \\
otolaryngologist & $5(2.0)$ \\
psychiatrist & $5(2.0)$ \\
cardiologist & $2(0.8)$ \\
neurosurgeon & $2(0.8)$ \\
Treatment administered & \\
none & $105(43.0)$ \\
NSAIDs & $108(44.3)$ \\
weak opioids & $43(17.6)$ \\
antiemetics & $31(12.7)$ \\
PPIs & $25(10.2)$ \\
paracetamol & $20(8.2)$ \\
corticosteroids & $16(6.6)$ \\
anxiolitics & $12(4.9)$ \\
antibiotics & $2(0.8)$ \\
one & \\
twosses of drugs (in ED) & $61(25.0)$ \\
fhree & $45(18.4)$ \\
\hline five & $24(9.8)$ \\
\hline
\end{tabular}

CT computed tomography, ECG electrocardiogram, ED emergency department NSAIDs non-steroidal anti-inflammatory drugs, PPIs proton pump inhibitors

\section{Discharge}

Discharge information are summarized in Table 5. At the time of discharge from ED the headache had not disappeared in $62.7 \%$ of the 244 patients and $43.9 \%$ of the patients had been discharged without a prescription. The most commonly prescribed medications for the treatment of headache were NSAIDs and paracetamol, administered to $33.2 \%$ and $11.1 \%$ of patients respectively, while triptans were prescribed to only $1.6 \%$. Monotherapy was prescribed more frequently than combination therapy with two agents $(44.7 \% \%$ vs $10.2 \%)$. Only $5.8 \%$ of patients were prescribed prophylactic treatment upon discharge. The most common post-discharge investigation was cerebral MRI, which was prescribed to $4.1 \%$ of patients, while in $92.6 \%$ of patients no further investigation was required.

\section{Follow-up in the headache Centre}

Information on follow-up visit to the headache centre is summarized in Table 6 . The average follow-up time at
Table 4 Factors that influence the length of stay in the emergency department LENGTH OF STAY IN ENERGENCY DEPARTMENT

\begin{tabular}{|c|c|c|c|c|c|}
\hline & mean & $\min$ & $\max$ & SD & $p$-value \\
\hline \multicolumn{6}{|l|}{ Time of arrival } \\
\hline 08:00-15:59 & 381 & 20 & 2212 & 327 & \multirow[t]{3}{*}{ NS } \\
\hline 16:00-23:59 & 393 & 37 & 1540 & 277 & \\
\hline 00:00-07:59 & 321 & 72 & 740 & 211 & \\
\hline \multicolumn{6}{|l|}{ Triage } \\
\hline white & 320 & 320 & 320 & . & \multirow[t]{4}{*}{ NS } \\
\hline green & 380 & 20 & 1540 & 282 & \\
\hline yellow & 387 & 37 & 2212 & 373 & \\
\hline red & 202 & 202 & 202 & . & \\
\hline \multicolumn{6}{|l|}{ Aura } \\
\hline no & 368 & 20 & 2212 & 291 & \multirow[t]{2}{*}{ NS } \\
\hline yes & 446 & 37 & 1412 & 360 & \\
\hline \multicolumn{6}{|l|}{ First aura } \\
\hline no & 527 & 133 & 1412 & 376 & \multirow[t]{2}{*}{0.014} \\
\hline yes & 325 & 37 & 1386 & 306 & \\
\hline \multicolumn{6}{|c|}{$\mathrm{SBP} \geq 140 \mathrm{mmHg}$} \\
\hline no & 383 & 20 & 2212 & 304 & \multirow[t]{2}{*}{ NS } \\
\hline yes & 373 & 37 & 1529 & 306 & \\
\hline \multicolumn{6}{|c|}{$\mathrm{DBP} \geq 90 \mathrm{mmHg}$} \\
\hline no & 389 & 20 & 2212 & 312 & \multirow[t]{2}{*}{ NS } \\
\hline yes & 271 & 92 & 479 & 114 & \\
\hline \multicolumn{6}{|l|}{ HEAD CT } \\
\hline no & 349 & 20 & 1540 & 270 & \multirow[t]{2}{*}{ NS } \\
\hline yes & 391 & 37 & 2212 & 314 & \\
\hline \multicolumn{6}{|l|}{ ECG } \\
\hline no & 359 & 20 & 1540 & 260 & \multirow[t]{2}{*}{ NS } \\
\hline yes & 531 & 37 & 2212 & 492 & \\
\hline
\end{tabular}

Other investifgations

$\begin{array}{llllll}\text { no } & 372 & 20 & 2212 & 294 & \text { NS } \\ \text { yes } & 510 & 37 & 1386 & 413 & \end{array}$

Neurological consultation

$\begin{array}{llllll}\text { no } & 333 & 20 & 2212 & 252 & <0.001 \\ \text { yes } & 580 & 37 & 1533 & 408 & \end{array}$

Other consultations

\begin{tabular}{cccccc} 
no & 359 & 20 & 2212 & 279 & 0.001 \\
yes & 625 & 115 & 1533 & 447 & \\
Treatment & & & & & \\
no & 385 & 41 & 1529 & 303 & NS \\
yes & 377 & 20 & 2212 & 305 & \\
\hline
\end{tabular}

$C T$ computed tomography, DBP diastolic blood pressure; NS not significant, $S B P$ systolic blood pressure, $S D$ standard deviation 
Table 5 Discharge from the emergency department

\begin{tabular}{lc}
\hline Headache at discharge & $153(62.7)$ \\
no & $91(37.3)$ \\
yes & \\
Drugs prescription & $107(43.9)$ \\
none & $81(33.2)$ \\
NSAIDs & $27(11.1)$ \\
paracetamol & $19(7.8)$ \\
weak opioids & $14(5.8)$ \\
prevention & $5(2.0)$ \\
corticosteroids & $4(1.6)$ \\
triptans & $2(0.8)$ \\
anxiolitics & $1(0.4)$ \\
antiemetics & $1(0.4)$ \\
antibiotics & \\
Classes of drugs (at discharge) & $109(44.7)$ \\
one & $25(10.2)$ \\
two & $3(1.2)$ \\
three & \\
Post-discharge investigations & $12(4.8)$ \\
brain MRI + angio-MRI & $2(0.8)$ \\
EEG & $2(0.8)$ \\
Holter blood pressure & $2(0.8)$ \\
\hline &
\end{tabular}

EEG electroencephalogram, MRI magnetic resonance imaging, NSAIDs nonsteroidal anti-inflammatory drugs

our headache centre was 8.9 days (range: $1-30$ ) after ED discharge and $4(1.6 \%)$ patients did not show up for the appointment. Considering the entire sample of 244 patients, $97.5 \%$ were new patients and $2.5 \%$ were already followed up at our headache clinic. All 240 patients who attended the follow-up appointment at our clinic were diagnosed with headache according to the ICHD [2, 20]. Most patients (66.7\%) were already aware of the diagnosis. A primary form of headache was diagnosed in $90 \%$ of patients, while a secondary headache was diagnosed

Table 6 Follow-up in the headache centre

\begin{tabular}{lc}
\hline Age at the onset (years) (SD) & $25(18.1)$ \\
\hline New patient to our headache clinic & $238(97.5)$ \\
Days since discarge & $8.9(7.2)$ \\
Familiarity for headache (yes) & $108(45.0)$ \\
Aware of their diagnosis (yes) & $160(66.7)$ \\
Headache days per month & $12.6(9.5)$ \\
OnabotulinumtoxinA for CM & 24 of $35(68.6)$ \\
Rehabilitation for $\mathrm{MOH}$ & 26 of $31(83.9)$ \\
\hline CM chronic migraine, $\mathrm{MOH}$ medication overuse headache, SD & \\
standard deviation &
\end{tabular}

in $10 \%$. The three most common primary headache diagnoses were migraine without aura (53.3\%), CM (14.6\%) and migraine without aura (14.2\%). The three most common diagnoses of secondary headache were medication overuse headache $(\mathrm{MOH})(12.7 \%)$, headache attributed to trauma (3.3\%) and headache attributed to cranial and/or cervical vascular disorder (2.5\%). A double diagnosis was given to $24.6 \%$ and a triple diagnosis to $1.2 \%$ of the patients. The most frequent combinations of two diagnoses were $\mathrm{CM}$ and $\mathrm{MOH}$ (11.7\%) followed by migraine with aura and migraine without aura $(9.6 \%)$. The most frequent combination of three diagnoses was $\mathrm{CM}$, $\mathrm{MOH}$ and migraine with aura $(0.8 \%)$ followed by $\mathrm{CM}$, $\mathrm{MOH}$ and headache attributed to cranial and/or cervical vascular disorder $(0.4 \%)$. The average age at the onset of their headache was 25 years (range: 6-89) and $45 \%$ had a family history of migraine. Patients were managed according to their headache diagnosis. All patients with a new migraine diagnosis were prescribed specific acute treatment for migraine (e.g., triptans), where it was not contraindicated. Those patients with a known diagnosis of migraine who had already experienced problems of efficacy and/or tolerability with the triptan they had already used, were prescribed another molecule belonging to the triptan class and/or analgesic combination (e.g., paracetamol plus caffeine or codeine). Both patients with migraine and tension-type headache with $>4$ attacks per month received oral prevention treatments according to international guidelines [21]. With regard to CM prevention, 24 (68.6\%) of 35 patients with this diagnosis were prescribed quarterly injections of onabotulinumtoxinA $[22,23]$ and $26(83.9 \%)$ of 31 patients with $\mathrm{MOH}$ started an in-patient withdrawal and rehabilitation protocol [24].

\section{Discussion}

We conducted a retrospective study on a consecutive sample of 244 patients observed in our tertiary headache centre after direct referral from the ED of our hospital, where they presented with a chief compliant of headache. Our aim was to analyzed the different stages of ED management of patients with headache to identify those deficiencies that can be overcome by a rapid referral to a headache clinic.

The first step of this journey is the need to make the correct diagnosis. The assessment of headache patients in the ED environment differs significantly from the assessment of headache patients in the clinic. Management of headache in an acute setting should focus on the exclusion of serious secondary causes, correct diagnosis, symptoms management and possibly the establishment of a continuing care plan [25]. The sense of urgency to exclude secondary and often life-threatening causes of headache, also due to time constraints due to the need 
for efficient patient management, may lead ED physicians to interrupt the diagnostic process on the differential diagnosis between primary and secondary headache. A Canadian study to assess the diagnostic accuracy of neurological complaints in ED found that in $35.7 \%$ of cases the initial ED diagnosis was not consistent with the final diagnosis made by a neurologist; among the most common misdiagnosed problems were primary headaches [26]. There was a high rate of discrepancy between the diagnosis made in our headache centre and the diagnosis made in ED. This discrepancy may have several reasons. ED physicians may be more interested in excluding serious causes of headache than in distinguishing different primary headaches or they are simply not familiar with the diagnostic criteria of ICHD. However, even if they were aware of the diagnostic criteria, ED physicians may not have adopted them because they intended to use the same treatment regardless of the diagnosis of primary headache. In addition, there is a possibility that ED physicians may simply accept the diagnosis of a triage nurse or not change the diagnosis already in the system. However, the interesting finding was that triage nurses used eleven different diagnosis, most of which simply describing a condition associated with headache, while ED physicians used only four diagnostic categories (Table 2). This finding provides further evidence of what ED physicians may consider to be their primary task, namely to rule out severe secondary headache rather than make a definitive diagnosis. The analyses of concordance among the three different diagnoses (triage, ED physician and headache centre) showed a significant moderate concordance only for the diagnosis of migraine and only between triage and headache centre. This latter finding is perhaps due to the fact that most patients $(66.7 \%)$ were already aware of their headache diagnosis and the triage nurse took the information obtained from the patients and used it to compile the triage diagnosis.

The second step of the journey are the diagnostic investigations that may be necessary to confirm the diagnostic suspect and establish consistent treatment. Head CT scans are commonly used to assess headache due to their rapid accessibility and diagnostic accuracy, but unnecessary head CT scans lead to a longer ED stay [27], exposure to radiations [28] and increased medical costs [29]. The use of CT scans for non-traumatic headache in the United States EDs has doubled in the last 20 years [30]. Up to $31 \%$ of patients who had headache underwent imaging [30] and head CT scans accounted for almost 50\% all CT scans in the United States EDs [31]. However, almost $95 \%$ of the CT scans carried out in the United States EDs between 1992 and 2001 showed no pathological results [12]. We found that $75 \%$ of patients who attended our ED with a major compliant of headache had a CT scan, which was negative in $93.4 \%$ of cases, while in the other cases the results were all considered accidental and not life-threatening (Table 3). However, this large use of CT scan in ED requires serious reflection. In fact, a recent study found that a 9.6\% decrease in the use of head CT scans for patients presenting to ED with a major headache complaint was not followed by an increase in deaths or missed diagnoses [32] This data provides convincing evidence that there is a possibility of safely decreasing CT scans for ED patients. Conversely, in support of CT use, another study found that patients who underwent a head CT scan during an initial ED visit were about half as likely to return to ED within 30 days than those who had not had CT [33]. Head imaging has been shown to have a positive influence on patients' fear and anxiety levels [34] and, by reassuring patients, CT scan prevent them from returning to ED. However, we can hypothesize that a rapid referral to a headache unit may have, at least in some patients, a similar reassuring effect, but avoiding the impact of the CT scan on the patient and the healthcare system.

The third step is the request for specialist consultations to add experience to the work of ED physicians. In our ED at least one neurologist is available $24 \mathrm{~h}$ a day, 7 days a week, both for the first line assessment if the prehospital assessment suggests a neurological condition, and for the second line, according to the judgement of a ED physician who is not a neurologist when the patient arrives. However, less than a fifth (19.3\%) of patients received a neurological consultation (Table 3). This rate was lower than in another study in French EDs, where one third of patients received a consultation with a neurologist [8]. The authors hypothesized that this may have been due to the fact that patients were experiencing an unusually severe attack or because a differential diagnosis was considered necessary for patients who had reported a first episode of headache. We can speculate that there may be a number of reasons for the fewer consultations in our study, including the doctor's certainty that a secondary headache is ruled out and knowledge of the possibility of a rapid referral to our headache clinic. Further consultations were requested for $8.2 \%$ of patients and the three most frequently consulted specialists were ophthalmologists (for aura), otolaryngologists (for sinusitis) and psychiatrists (for comorbid conditions). However, receiving specialist consultations, both neurological and other, was the only factor that was significantly associated with a longer stay in ED (Table 4). On the contrary, the complaint of the first aura in life was associated with a shorter stay in ED. It is possible that when faced a patient who reported having previously had other episodes of aura, the ED doctor was reassured on the benignity of the symptom, while in the case of the first aura the doctor was more 
cautious and felt the urgency to handle the case. This fact could also indicate an inadequate knowledge of the diagnostic criteria of primary headaches in general, and specifically the clinical spectrum of migraine.

The fourth and fundamental step in the management of headaches in ED is the pharmacological treatment. Patients with migraine or other headaches have the third highest selfreported pain score of all patients presenting to ED with a painful condition [35]. Consistently, the American Migraine Prevalence and Prevention (AMPP) study found that unbearable pain was the most common reason for the use of ED for migraine [36]. Patients attending ED with a headache pattern similar to previous migraine attacks generally do not require, or do not want, diagnostic tests, but expect rapid and effective management of their headache and any misdiagnosis can lead to generalized pain treatment rather than of specific treatment for migraine [18]. More than 20 different drugs and drug combinations are used to treat migraine in $E D$, including migraine-specific drugs (e.g., sumatriptan and dihydroergotamine), dopamine antagonists (e.g., metoclopramide, chlorpromazine and prochlorperazine), NSAIDs, opioids, corticosteroids, and anti-histamines (e.g., diphenhydramine and promethazine) [37]. In our ED, the most commonly prescribed pharmacological agents were NSAIDs and weak opioids, administered to $44.3 \%$ and $17.6 \%$ of patients respectively, followed by paracetamol, which was administered to $8.2 \%$ of patients (Table 3). Treatment of the associated symptoms included antiemetics and anxiolytics, administered to $12.7 \%$ and $4.9 \%$ of patients respectively. Another study conducted in Europe showed opposite use of NSAIDs (42.9\%) and non-opioid analgesics (61.2\%) and lower use of antiemetics (8\%) and anxiolytics (3\%) [8]. In the above mentioned study, approximately $9 \%$ of patients did not receive any pharmacological treatment and triptans were not administered frequently (11.2\%) [8]. In our sample, about $43 \%$ of patients did not receive any medications and no triptans (or ergotamines) were administered. However, the underutilization of headache medications in ED is not limited to European countries. A survey conducted in a university hospital ED in the United States found an equally high percentage of patients (38\%) who received neither drugs nor intravenous fluids [18].

The role of the ED physician is not only to rule out a secondary headache disorder but to provide adequate headache treatment; but the latter goal is not always accomplished. In our study, headache had not disappeared at the time of ED discharge in $62.7 \%$ of the 244 patients. This rate, dramatic in itself, was still lower than that of another study in the French department, where migraine had not disappeared at the time of discharge from ED in $80.2 \%$ of patients [8]. There are significant variations in headache management between and within EDs due to lack of strong recommendations, physician comfort and familiarity with specific medications, belief in efficacy, concern about short-term side effects, and patient demand [37-39]. Only recently, the Canadian Headache Society and the American Headache Society have provided evidence-based therapeutic recommendations for $\mathrm{mi}$ graine requiring treatment in emergency settings [40, 41].

The fifth and final step in the management of headaches in ED is discharge. Significant evidence suggests that migraine discharge management is often suboptimal. About $40 \%$ of emergency physicians never prescribed triptans on discharge [42], about $60 \%$ of patients had no documented discharge medications and $2 / 3$ of patients did not receive a medical follow-up recommendation [18]. These malpractices contribute to the high rate of ED return visits noted among migraine patients [43]. Another study found a high percentage of patients (34.7\%) discharged without a prescription and again the most commonly prescribed drugs were analgesics and NSAIDs rather than migraine-specific drugs [8]. Our data, in line with the previous literature, showed that $43.9 \%$ of patients were discharged without a prescription, while the most commonly prescribed drugs for the treatment of headache were NSAIDs (33.2\%) and paracetamol (11.1\%), while triptans were prescribed only to 1.6\% (Table 5).

Considering what has been discussed earlier on the journey through ED of a patient complaining of headache, a fast track between ED and a headache clinic is a step forward in headache management. Headache is the most common disorder among patients presenting to ED with neurological complaints [44] and although in most cases it is discharged as a non-urgent disorder, these patients feel they need urgent medical evaluation [45]. On the contrary, migraine patients, especially those with a known diagnosis, should have the idea that their headache is not a life-threatening condition and if they get to ED it is more because of access problems and less because of a perceived need for emerging treatment. Inappropriate use of ED leads to overcrowding and consequently an increase in intervention times, which is one of the main reasons for leaving ED prematurely [46], especially among patients with a compliant of headache [47]. This suggests that a healthcare system could reduce ED visits among migraineurs by increasing the availability of urgent care or walk-in appointments [48].

Further evidence of the importance of rapid referral to a headache centre comes from an analysis of ED use by migraine patients. The AMPP study showed that only a small subset of respondents used ED for the treatment of severe headaches in the previous 12 months: $3 \%$ visited the ED once and another 3\% visited ED more than once [36]. Interestingly, in a previous study, we showed that among the 548 migraine patients who attended our headache clinic and were undergoing continuous treatment and regular follow-up visits, only $0.9 \%$ of them 
entered the ED during the entire 2-years observation period [49]. This is explained by the fact that migraine prevention and prescription of migraine-specific rescue therapies reduce the use of resources in general, and ED visits in particular [50-52]. In addition to improving the health and quality of life of patients, a preferential route between ED and the headache clinic can lead to significant cost savings, considering that ED care is considerably more expensive than both hospital outpatient care and office-based outpatient care. At a time of economic hardship and availability of new and expensive treatments, such as monoclonal antibodies targeting the calcitonin gene-related peptide, a virtuous allocation of economic resources becomes mandatory [53].

\section{Limitations}

The study has several potential limitations. First, there are inherent limitations related to the use of the data collected primarely for clinical care, such as errors in recording some information that could be perceived as secondary importance in the particular setting of ED. However, we believe that the variables of primary interest in this analysis, including socio-demographic characteristics, diagnostic procedures, specialist consultations and drugs should not have been subject to inaccurate recording. Secondly, the enrollment period was between January 1, 2015 and December 31, 2018 and, for this reason, most patients were diagnosed according to the beta version of the ICHD-III published in 2013, while the definitive version was published in early 2018 . Thirdly, the decision of ED physicians whether or not to refer a patient discharged from the ED for a severe headache to our headache centre is totally personal and independent. As a result, there is a possibility that patients may have been referred mainly by some physicians and not by others and that this may introduce a selection bias towards one type of patient rather than another. Finally, this study was conducted in a single university hospital for tertiary care and our results may not be generalized to other countries or even to other Italian regions or to other EDs that may have different organizational and therapeutic protocols.

\section{Conclusions}

The vast majority of patients who went to the emergency room complaining of a headache received the same treatment regardless of the cause of the headache and for this reason in many cases the headache had not yet resolved at the time of discharge. We have shown a high rate of misdiagnosis of primary headaches and a short route between ED and the headache center is of primary importance to help the patient achieve a definitive diagnosis and appropriate treatment. Reducing the number of emergency visits for primary headaches, and in particular migraine headaches, is the goal and easy and rapid referral to headache specialists can prevent further recourse to ED. In addition, an implementation of referral from ED to the headache center of the same hospital, if present, can increase the quality of patient management and, by sharing information about hospital's EMRs, can avoid the need to repeat diagnostic investigations and reduce time and expense, thus leading to a better allocation of public resources.

\section{Abbreviations \\ BP: Blood pressure; CGRP: Calcitonin gene-related peptide; CM: Chronic migraine; CT: Computed tomography; ECG: Electrocardiogram; \\ ED: Emergency department; EEG: Electroencephalogram; EM: Episodic migraine; EMR: Electronic medical records; ICHD: International classification of headache disorders; MOH: Medication overuse headache; MRI: Magnetic resonance imaging; NSAIDs: Non-steroidal anti-inflammatory drugs; TACs: Trigeminal autonomic cephalalgias}

\section{Acknowledgements}

Not applicable.

\section{Authors' contributions}

AN: study design, data acquisition, data analysis and interpretation, drafting the manuscript. VS: study design, data acquisition. PS: statistical analysis. PM: conception of the study and revising the manuscript critically. All authors read and approved the final manuscript.

\section{Funding}

This paper was not funded.

Availability of data and materials

Dataset available from the corresponding author on reasonable request.

Ethics approval and consent to participate

Study protocol was submitted to the Ethics Committee.

Consent for publication

Not applicable.

\section{Competing interests}

A. Negro received travel grants, consulting fees and speaking fees from Allergan, Eli Lilly, Novartis, and TEVA.

P. Martelletti received travel grants, consulting fees and speaking fees from Allergan, Amgen, Eli Lilly, Novartis, and TEVA.

The authors have no other relevant affiliations or financial involvement with any organization or entity with a financial interest in or conflict with the subject matter or materials discussed in this manuscript apart from those disclosed.

\section{Author details}

${ }^{1}$ Department of Clinical and Molecular Medicine, Sapienza University, Rome, Italy. ${ }^{2}$ Regional Referral Headache Centre, Sant'Andrea Hospital, Rome, Italy.

${ }^{3}$ Department of Statistical Sciences, Sapienza University of Rome, Rome, Italy.

Received: 17 January 2020 Accepted: 6 March 2020

Published online: 14 March 2020

\section{References}

1. Evans RW, Friedman BW (2011) Headache in the emergency department. Headache. 51(8):1276-1278

2. Headache classification committee of the International Headache Society (IHS) (2018) The international classification of headache disorders, 3rd edition. Cephalalgia 38(1):1-211

3. GBD 2016 Disease and injury incidence and prevalence collaborators (2017) Global, regional, and national incidence, prevalence, and years lived with disability for 328 diseases and injuries for 195 countries, 1990-2016: a systematic analysis for the global burden of disease study 2016. Lancet 390(10100):1211-1259 
4. Stewart WF, Wood GC, Manack A, Varon SF, Buse DC, Lipton RB (2010) Employment and work impact of chronic migraine and episodic migraine. J Occup Environ Med 52(1):8-14

5. Blumenfeld AM, Varon SF, Wilcox TK, Buse DC, Kawata AK, Manack A, Goadsby PJ, Lipton RB (2011) Disability, HRQoL and resource use among chronic and episodic migraineurs: results from the international burden of migraine study (IBMS). Cephalalgia. 31(3):301-315

6. Cerbo R, Villani V, Bruti G, Di Stani F, Mostardini C (2005) Primary headache in emergency department: prevalence, clinical features and therapeutical approach. J Headache Pain 6(4):287-289

7. Friedman BW, Hochberg ML, Esses D, Grosberg B, Corbo J, Toosi B, Meyer RH, Bijur PE, Lipton RB, Gallagher EJ (2007) Applying the International Classification of Headache Disorders to the emergency department: an assessment of reproducibility and the frequency with which a unique diagnosis can be assigned to every acute headache presentation. Ann Emerg Med 49(4):409-419 419.e1-9

8. Valade D, Lucas C, Calvel L, Plaisance P, Derouet N, Meric G, Lanteri-Minet M, Giroud M (2011) Migraine diagnosis and management in general emergency departments in France. Cephalalgia 31(4):471-480

9. Munoz-Ceron J, Marin-Careaga V, Peña L, Mutis J, Ortiz G (2019) Headache at the emergency room: etiologies, diagnostic usefulness of the ICHD 3 criteria, red and green flags. PLoS One 14(1):e0208728

10. Doretti A, Shestaritc I, Ungaro D, Lee Jl, Lymperopoulos L, Kokoti L, Guglielmetti M, Mitsikostas DD, Lampl C (2019) School of Advanced Studies of the European Headache Federation (EHF-SAS). Headaches in the emergency department - a survey of patients' characteristics, facts and needs. J Headache Pain 20(1):100

11. National Center for Health Statistics. Centers for Disease Control and Prevention. Available at: www.cdc.gov/nchs/data/nhamcs/web_tables/2 016_ed_web_tables.pdf. Accessed 24 Feb 2020

12. Goldstein JN, Camargo CA Jr, Pelletier AJ, Edlow JA (2006) Headache in United States emergency departments: demographics, work-up and frequency of pathological diagnoses. Cephalalgia 26(6):684-690

13. Locker TE, Thompson C, Rylance J, Mason SM (2006) The utility of clinical features in patients presenting with nontraumatic headache: an investigation of adult patients attending an emergency department. Headache. 46(6):954-961

14. Sempere-Selva T, Peiró S, Sendra-Pina P, Martínez-Espín C, López-Aguilera I (2001) Inappropriate use of an accident and emergency department: magnitude, associated factors, and reasons--an approach with explicit criteria. Ann Emerg Med 37(6):568-579

15. Miyazawa A, Maeno T, Shaku F, Tsutsumi M, Kurihara H, Takayashiki A, Kohno M, Suzuki M, Maeno T (2019) Inappropriate use of the emergency department for nonurgent conditions: patient characteristics and associated factors at a Japanese hospital. J Gen Fam Med 20(4):146-153

16. Minen MT, Loder E, Friedman B (2014) Factors associated with emergency department visits for migraine: an observational study. Headache. 54(10):1611-1618

17. Blumenthal HJ, Weisz MA, Kelly KM, Mayer RL, Blonsky J (2003) Treatment of primary headache in the emergency department. Headache 43(10):1026-1031

18. Gupta MX, Silberstein SD, Young WB, Hopkins M, Lopez BL, Samsa GP (2007) Less is not more: underutilization of headache medications in a university hospital emergency department. Headache. 47(8):1125-1133

19. Reboussin DM, Allen NB, Griswold ME, Guallar E, Hong Y, Lackland DT, Miller EPR 3rd, Polonsky T, Thompson-Paul AM, Vupputuri S (2018) Systematic review for the 2017 ACC/AHA/AAPA/ABC/ACPM/AGS/APhA/ASH/ASPC/ NMA/PCNA guideline for the prevention, detection, evaluation, and Management of High Blood Pressure in adults: a report of the American College of Cardiology/American Heart Association task force on clinical practice guidelines. Hypertension 71(6):e116-e135

20. Headache Classification Committee of the International Headache Society (IHS) (2013) The international classification of headache disorders, 3rd edition (beta version). Cephalalgia 33:629-808

21. Silberstein SD, Holland S, Freitag F, Dodick DW, Argoff C (2012) Evidencebased guideline update: pharmacologic treatment for episodic migraine prevention in adults. Neurology 78:1337-1345

22. Negro A, D'Alonzo L, Lala N, Martelletti P (2015) A 2-year prospective evaluation study on onabotulinumtoxinA $155 \mathrm{U}$ in chronic migraine. SpringerPlus 4:826

23. Negro A, Curto M, Lionetto L, Martelletti P (2016) A two years open-label prospective study of onabotulinumtoxinA $195 \mathrm{U}$ in medication overuse headache: a real-world experience. J Headache Pain 17:1
24. Negro A, Curto M, Lionetto L, Guerzoni S, Pini LA, Martelletti P (2017) A critical evaluation on $\mathrm{MOH}$ current treatments. Curr Treat Options Neurol 19(9):32

25. Ward TN, Levin M, Phillips JM (2001) Evaluation and management of headache in the emergency department. Med Clin North Am 85(4):971-985

26. Moeller JJ, Kurniawan J, Gubitz GJ, Ross JA, Bhan V (2008) Diagnostic accuracy of neurological problems in the emergency department. Can J Neurol Sci 35(3):335-341

27. Kerber KA, Schweigler L, West BT, Fendrick AM, Morgenstern LB (2010) Value of computed tomography scans in ED dizziness visits: analysis from a nationally representative sample. Am J Emerg Med 28(9):1030-1036

28. Colang JE, Killion JB, Vano E (2007) Patient dose from CT: a literature review. Radiol Technol 79(1):17-26

29. Wang X, You JJ (2013) Head CT for nontrauma patients in the emergency department: clinical predictors of abnormal findings. Radiology. 266(3):783-790

30. Gilbert JW, Johnson KM, Larkin GL, Moore CL (2012) Atraumatic headache in US emergency departments: recent trends in CT/MRI utilisation and factors associated with severe intracranial pathology. Emerg Med J 29(7):576-581

31. Centers for Disease Control and Prevention. National ambulatory medical care survey: 2010 summary tables. Available at: https://www.cdc.gov/nchs/data/ ahcd/namcs_summary/2010 namcs web tables.pdf. Accessed 24 Feb 2020

32. Miller DG, Vakkalanka P, Moubarek ML, Lee S, Mohr NM (2018) Reduced computed tomography use in the emergency department evaluation of headache was not followed by increased death or missed diagnosis. West J Emerg Med 19(2):319-326

33. Patterson BW, Pang PS, AlKhawam L, Hamedani AG, Mendonca EA, Zhao $Y Q$, Venkatesh AK (2016) The association between use of brain $C T$ for Atraumatic headache and 30-day emergency department Revisitation. AJR Am J Roentgenol 207(6):W117-W124

34. Howard L, Wessely S, Leese M, Page L, McCrone P, Husain K, Tong J, Dowson A (2005) Are investigations anxiolytic or anxiogenic? A randomised controlled trial of neuroimaging to provide reassurance in chronic daily headache. J Neurol Neurosurg Psychiatry 76(11):1558-1564

35. Lucado J, Paez K, Elixhauser A (2006) Headaches in U.S. Hospitals and Emergency Departments, 2008: Statistical brief \#111. Healthcare Cost and Utilization Project (HCUP) Statistical Briefs. Agency for Healthcare Research and Quality (US), Rockville

36. Friedman BW, Serrano D, Reed M, Diamond M, Lipton RB (2009) Use of the emergency department for severe headache. A population-based study. Headache. 49(1):21-30

37. Friedman BW, West J, Vinson DR, Minen MT, Restivo A, Gallagher EJ (2015) Current management of migraine in US emergency departments: an analysis of the National Hospital Ambulatory Medical Care Survey. Cephalalgia. 35(4):301-309

38. Giamberardino MA, Affaitati G, Costantini R, Guglielmetti M, Martelletti P (2020) Acute headache management in Emergency Department. A narrative review. Int Emerg Med 15(1):109-117

39. Vinson DR, Hurtado TR, Vandenberg JT, Banwart L (2003) Variations among emergency departments in the treatment of benign headache. Ann Emerg Med 41(1):90-97

40. Orr SL, Aubé M, Becker WJ, Davenport WJ, Dilli E, Dodick D, Giammarco R, Gladstone J, Leroux E, Pim H, Dickinson G, Christie SN (2015) Canadian headache society systematic review and recommendations on the treatment of migraine pain in emergency settings. Cephalalgia. 35(3):271-284

41. Orr SL, Friedman BW, Christie S et al (2016) Management of adults with acute migraine in the emergency department: the American headache society evidence assessment of parenteral pharmacotherapies. Headache 56:911-940

42. Nijjar SS, Pink L, Gordon AS (2011) Examination of migraine management in emergency departments. Pain Res Manag 16(3):183-186

43. Maizels M (2002) Health resource utilization of the emergency department headache "repeater". Headache. 42(8):747-753

44. Royl G, Ploner CJ, Möckel M, Leithner C (2010) Neurological chief complaints in an emergency room. Nervenarzt. 81(10):1226-1230

45. Harenberg L, Oßwald HM, Jaschonek H, Nagel S (2019) Self-assessment of treatment urgency on presentation to a neurological emergency department: results of a patient survey. Nervenarzt. 90(2):175-182

46. van der Linden $M C$, Lindeboom $R$, van der Linden $N$, van den Brand $C L$, Lam RC, Lucas C, Rhemrev SJ, de Haan R, Goslings JC (2014) Walkouts from the emergency department: characteristics, reasons and medical care needs. Eur J Emerg Med 21(5):354-359 
47. Hoyer C, Stein P, Alonso A, Platten M, Szabo K (2019) Uncompleted emergency department care and discharge against medical advice in patients with neurological complaints: a chart review. BMC Emerg Med 19(1):52

48. Pellesi L, Benemei S, Favoni V, Lupi C, Mampreso E, Negro A, Paolucci M, Steiner TJ, Ulivi M, Cevoli S, Guerzoni S (2017) Quality indicators in headache care: an implementation study in six Italian specialist-care centres. $J$ Headache Pain 18(1):55

49. Negro A, Sciattella P, Rossi D, Guglielmetti M, Martelletti P, Mennini FS (2019) Cost of chronic and episodic migraine patients in continuous treatment for two years in a tertiary level headache Centre. J Headache Pain 20(1):120

50. Lofland JH, Kim SS, Batenhorst AS, Johnson NE, Chatterton ML, Cady RK, Kaniecki R, Nash DB (2001) Cost-effectiveness and cost-benefit of sumatriptan in patients with migraine. Mayo Clin Proc 76(11):1093-1101

51. Silberstein SD, Winner PK, Chmiel JJ (2003) Migraine preventive medication reduces resource utilization. Headache. 43(3):171-178

52. Láinez MJ (2009) The effect of migraine prophylaxis on migraine-related resource use and productivity. CNS Drugs 23(9):727-738

53. Negro A, Martelletti P (2019) Patient selection for migraine preventive treatment with anti-CGRP(r) monoclonal antibodies. Expert Rev Neurother 19(8):769-776

\section{Publisher's Note}

Springer Nature remains neutral with regard to jurisdictional claims in published maps and institutional affiliations.

Ready to submit your research? Choose BMC and benefit from:

- fast, convenient online submission

- thorough peer review by experienced researchers in your field

- rapid publication on acceptance

- support for research data, including large and complex data types

- gold Open Access which fosters wider collaboration and increased citations

- maximum visibility for your research: over $100 \mathrm{M}$ website views per year

At BMC, research is always in progress.

Learn more biomedcentral.com/submissions 